\title{
Following Endocrine-Disrupting Effects on Gene Expression in Xenopus laevis
}

\author{
Petra Spirhanzlova, ${ }^{1}$ Michelle Leemans, ${ }^{1}$ Barbara A. Demeneix, ${ }^{1,2}$ and Jean-Baptiste Fini ${ }^{1,2}$ \\ ${ }^{1}$ Evolution des Régulations Endocriniennes, Département "Adaptation du Vivant," UMR 7221 MNHN/CNRS, \\ Sorbonne Université, Paris 75006, France
}

Endocrine-disrupting chemicals (EDCs), found in all categories of chemicals, are suspected to be a cause of declining well-being and human health, both as single molecules and as mixtures. It is therefore necessary to develop high throughput methods to assess the endocrine-disrupting potential of multiple chemicals currently on the market that are as yet untested. An advantage of in vivo chemical screening is that it provides a full spectrum of physiological impacts exerted by a given chemical. Xenopus laevis is an ideal model organism to test thyroid axis disruption in vivo as thyroid hormones (THs) are highly conserved across vertebrates and orchestrate tadpole metamorphosis. In particular, NF stage 45 Xenopus laevis are most apt for in vivo screening as at this stage the tadpoles possess all the main elements of thyroid hormone signaling (thyroid receptors, deiodinases transporters) and are metabolically competent, while fitting into multiple well plates, allowing the use of small amounts of test chemicals. One way to assess the endocrine-disrupting potential of chemicals or mixtures thereof is to analyze gene expression in organisms after a short time exposure to the chemical(s). Here we describe a protocol using Xenopus laevis embryos to detect endocrine disruption of the thyroid axis by analysis of gene expression and an alternative protocol for fluorescence read-out using a transgenic GFP-expressing Xenopus laevis line. Taken together, these methods allow detection of subtle changes in $\mathrm{TH}$ signaling by EDCs that either activate or inhibit TH signaling in vivo.

\section{MATERIALS}

It is essential that you consult the appropriate Material Safety Data Sheets and your institution's Environmental Health and Safety Office for proper handling of equipment and hazardous materials used in this protocol.

RECIPES: Please see the end of this protocol for recipes indicated by $<R>$. Additional recipes can be found online at http://cshprotocols.cshlp.org/site/recipes.

\section{Reagents}

\section{Agilent RNA 6000 Pico Kit}

Aquatic system water, chlorine-free

Filter through an aquatic water system (e.g., Veolia custom system).

Dimethyl sulfoxide (DMSO; CAS 67-68-5)

\footnotetext{
${ }^{2}$ Correspondence: fini@mnhn.fr; bdem@mnhn.fr

From the Xenopus collection, edited by Hazel L. Sive.

(c) 2019 Cold Spring Harbor Laboratory Press

Cite this protocol as Cold Spring Harb Protoc; doi:10.1101/pdb.prot098301
} 
Endocrine-disrupting compound(s) of interest dissolved in DMSO to a concentration $10,000 \times$ higher than the final test concentration

Ethyl 3-aminobenzoate methanesulfonate salt (MS222; CAS 886-86-2) solution $(1 \mathrm{~g} / \mathrm{L})<\mathrm{R}>$ Adjust $\mathrm{pH}$ between 7.2 and 8.

Evian water in $75 \mathrm{cL}$ glass bottle or another mineral water with reproducible quality High capacity cDNA RT kit (Life technologies 4368813) or Reverse Transcription Master Mix (Fluidigm 100-6299)

Human chorionic gonadotropin (hCG; CAS 9002-61-3; Sigma-Aldrich CG5-1VL)

Ice

Liquid nitrogen

Milli-Q reference water

Nuclease-free water (ThermoFisher Scientific AM9937)

Power SYBR Master Mix (Life Technologies 4368708)

Primers, 10 pм (Eurofins; see Table 1)

RNAse-free $0.8 \%$ agarose gel (optional; see Step 22)

RNAqueous-micro kit (Life Technologies AM1931)

RnaseZap (ThermoFisher Scientific AM9780; optional; see Step 17)

Sodium hydroxide (NaOH 0.1 N; CAS 1310-73-2; optional; see Step 17)

Transgenic Xenopus laevis line expressing GFP (e.g., $\mathrm{Tg}$ (thibz:GFP) [Fini et al. 2007]) (optional; see Step 36)

3,3',5-Triiodo-L-thyronine sodium salt $\left(\mathrm{T}_{3}\right)$ solution $<\mathrm{R}>$

Xenopus laevis mature male and female (WT) or Xenopus laevis NF stage 45 tadpoles

Equipment

96-well black, conical well plate (Greiner Bio-one 651209; optional; see Step 38)

384-well clear hardshell plate (ThermoFisher Scientific 4309849)

Air pump and stone

Adhesive covers for 384 well plates (ThermoFisher Scientific 4311971)

BioAnalyzer (Agilent)

Black foil to cover breeding chamber

TABLE 1. Primers for genes involved in thyroid signaling in Xenopus

\begin{tabular}{ll}
\hline thra $\mathrm{F}$ & CGCCTTGGTCTCTTCGGAT \\
thra $\mathrm{R}$ & CCCATACATTGGCTGTTCTTTCTTT \\
thrb $\mathrm{F}$ & AAGAGTGGTTGATTTTGCAAAA \\
thrb $\mathrm{R}$ & AGGGACATGATCTCCATACAACAG \\
dio $1 \mathrm{~F}$ & CAGCAGATGAATGGGGATTGA \\
dio $1 \mathrm{R}$ & TGTCTAACACTACTGGGCAAGAAGGT \\
dio $2 \mathrm{~F}$ & AGGCTGAGTGTGGACTTGCT \\
dio $2 \mathrm{R}$ & TGACCTGCTTGTAGGCATCCA \\
dio3 $\mathrm{F}$ & CACAAAAAGTGCGACCAAACG \\
dio3 $\mathrm{R}$ & GCCTTGTTGCAGTTTACT \\
thibz $\mathrm{F}$ & ACCTCCACAGAATCAGCAGC \\
thibz $\mathrm{R}$ & GCAGAGAACGAGCAAGGAGT \\
klf9 $\mathrm{F}$ & TGTGGCAAAGTTTATGGGAAGTCT \\
klf9 $\mathrm{R}$ & GGCGTTCACCTGTATGGACTCT \\
lat2 $\mathrm{F}$ & CAAGAGATGCACTAAAGCTGCC \\
lat2 $\mathrm{R}$ & CCTTGCTTCCAACACCCGAT \\
odc $\mathrm{F}$ & TGAAAACATGGGTGCCTACA \\
odc $\mathrm{R}$ & AAGTTCCATTCCGCTCTCCT \\
ef1a $\mathrm{F}$ & TGGATATGCCCCTGTGTTGGATT \\
ef1a $\mathrm{R}$ & TCCACGCACATTGGCTTTCCT \\
&
\end{tabular}


P. Spirhanzlova et al.

Microcentrifuge (e.g., Eppendorf 5417 R)

Dissecting tools (forceps, etc.)

Fluorescent microscope equipped with $25 \times$ objective and long pass GFP filter (optional; see Step 40)

Freezer $\left(-20^{\circ} \mathrm{C}\right)$

Glass aquarium $(25 \mathrm{~L})$

GraphPad Prism 6

Greiner polypropylene capped tubes (50 mL; Greiner Bio-one 227261)

Throughout the protocol, polypropylene tubes should be washed with dechlorinated aquatic system water before use.

ImageJ (optional; Step 42)

Incubator

Microcentrifuge tubes $0.2-1.7 \mathrm{~mL}$, flip top, $100 \%$ polypropylene

MS Excel

Multidistribution pipette

NanoDrop (ThermoScientific)

Needles $(0.4 \times 20$ mm; Terumo NN2719R)

PCR machine (Bio-Rad)

PCR tube strips (0.2 mL; Eppendorf)

Pipette tips $(0.2-5000 \mu \mathrm{L})$

Plastic grid (optional; see Step 1)

Plastic transfer bucket

QC Capture pro (QImaging; optional; see Step 40)

QuantStudio 6 flex QPCR machine (Life Technologies)

QuantStudio Real-Time PCR Software

Syringes $1 \mathrm{~mL}$ (Terumo SS+01H1)

Transfer pipettes with large bulb (1 mL; Samco Scientific 222-1s)

Transfer pipettes with extended fine tip (1 mL; Samco Scientific 223-1S)

Transparent flat six-well plates (TPP, Switzerland, 1613470)

Vortex mixer

\section{METHOD}

Breeding

1. Prepare a breeding chamber by filling a glass tank with dechlorinated water. The temperature of the water should be equilibrated to $21^{\circ} \mathrm{C}$. Place the breeding chamber in a quiet place.

Placing a grid at the bottom of the tank will prevent adults from eating the eggs (optional).

2. Place one Xenopus laevis female and one Xenopus laevis male in plastic transport buckets filled with dechlorinated water equilibrated to $21^{\circ} \mathrm{C}$.

The probability of successful mating is increased by selecting a female with a prominent cloaca and pearshaped body and a male with dark nuptial pads on the forelimbs.

3. Prepare a solution of hCG by transferring all liquid provided in the kit into the vial containing the hCG powder using a syringe. This will create a solution with a final concentration of $1000 \mathrm{U} / \mathrm{mL}$. Vortex to ensure that the powder is fully dissolved.

Once prepared, the chorion gonadotropin solution can be stored at $-20^{\circ} \mathrm{C}$ until the next usage. Do not thaw it more than 3 times.

4. Inject the female with a starting dose of 500 units and the male with 50 units of hCG solution into the dorsal lymph sac located at the lower back of the animal between the stitch marks using $0.4 \times$ $20 \mathrm{~mm}$ needles. Gently massage the area after injection. 
5. Place the male and female together into the previously prepared breeding chamber. Wrap the tank with black foil to ensure that the couple won't be disturbed and place a weight (e.g., brick) on top of the lid.

6. Leave the couple overnight. On the next day verify amplexus (mating position in which the male clasps the female with his front limbs around the waist to align cloacae) and egg-laying.

See Troubleshooting.

7. Return the frogs to their normal housing condition at the end of the next day.

Xenopus laevis males can next be used for breeding after 2 wk, whereas Xenopus laevis females should not be used for breeding for at least 4-6 mo.

8. Leave the eggs in the breeding tank with an air pump and air stone for a week until the tadpoles reach stage 45 (Nieuwkoop and Faber 1994). Renew the water in the breeding chamber if it is turbid and maintain a stable temperature of $21^{\circ} \mathrm{C}$.

See Troubleshooting.

\section{Chemical Exposure}

In this protocol, tadpoles are exposed to chemicals in the absence or presence of $T_{3}(5 \mathrm{~nm})$. The $T_{3}$ addition stimulates production of TRß (Thyroid Hormone Receptor Beta) from stage 37 onwards (Turque et al. 2005; Fini et al. 2012, 2017), thereby amplifying responses.

A thyroid hormone agonist is a good positive control when considering experiments in relation to the thyroid axis. Most of the time $5 \mathrm{~nm} T_{3}$ solution is used as it is the actual hormone acting at the receptor level. An indirect induction could be studied using $T_{4}$ instead of $T_{3}$. As a control of nonthyroid hormone related action, we usually use NH-3 (Lim et al. 2002), the only TR antagonist (in presence of $T_{3}$ ) that has been described.

All steps are performed at room temperature unless specified.

9. Dilute the stock solutions of compound(s) of interest in DMSO to a concentration 10,000 $\times$ higher than the final test concentration. Usually $0.2-1.7 \mathrm{~mL} 100 \%$ polypropylene microcentrifuge tubes are used for this purpose. If you are testing a range of concentrations of a chemical, prepare a cascade dilution in DMSO starting from the highest concentration of stock solution (illustrated in Fig. 1A).

The $10,000 \times$ stock solution can be prepared fresh daily or aliquoted and stored at $-20^{\circ} \mathrm{C}$ to avoid repeated thawing and freezing. Use a new aliquot each day.

Not all chemicals are soluble in DMSO. Some dissolve more easily in water, ethanol, or methanol. The appropriate solvent should be checked using information available on the product. When a solvent other than DMSO is used, adjust the solutions of control groups accordingly, for example by using $0.01 \%$ ethanol or methanol when solutions are prepared in ethanol or methanol, respectively.

10. Rinse two $50 \mathrm{~mL}$ polypropylene tubes with dechlorinated aquatic system water. Add $10 \mathrm{~mL}$ of Evian water to one of these tubes and $10 \mathrm{~mL} 5 \mathrm{~nm} \mathrm{~T}$ solution to the other tube. Add $1 \mu \mathrm{L}$ of $10,000 \times$ concentrated test solution using a pipette with a $10 \mu \mathrm{L}$ tip to create a $1 \times$ test solution. Vortex the solutions thoroughly.

11. Rinse all wells of a six-well plate with dechlorinated aquatic system water. Add $8 \mathrm{~mL}$ of Evian water to each well. Using a $1 \mathrm{~mL}$ transfer pipette with large bulb (polyethylene) with the open section cut (widen the tip of the transfer pipette by scalpel or scissors to diameter of at least $4 \mathrm{~mm}$ ), transfer 15 st.45 tadpoles per well of the six-well plate (containing Evian water).

Throughout the protocol, transfer tadpoles as described in this step.

In this standard assay, 15 tadpoles are used per exposure group per replicate. In this protocol one chemical of interest is tested under two conditions: in the absence and presence of $5 \mathrm{~nm} T_{3}$. A standard test plate therefore contains one well corresponding to a control (Evian water $+0.01 \%$ DMSO), one well containing the chemical of interest diluted in Evian water, one well containing $5 \mathrm{~nm} T_{3}+0.01 \%$ DMSO, and one well corresponding to the chemical of interest diluted in $5 \mathrm{~nm} T_{3}$. If more than one concentration of the chemical of interest is tested, one control and one $5 \mathrm{~nm} T_{3}$ group for the experiment are sufficient.

12. Remove the liquid from all six wells using a transfer pipette. To one well, add $8 \mathrm{~mL}$ of $1 \times$ chemical of interest in Evian water prepared in Step 10 using either a P5000 pipette (twice) or a $10 \mathrm{~mL}$ 
P. Spirhanzlova et al.

A
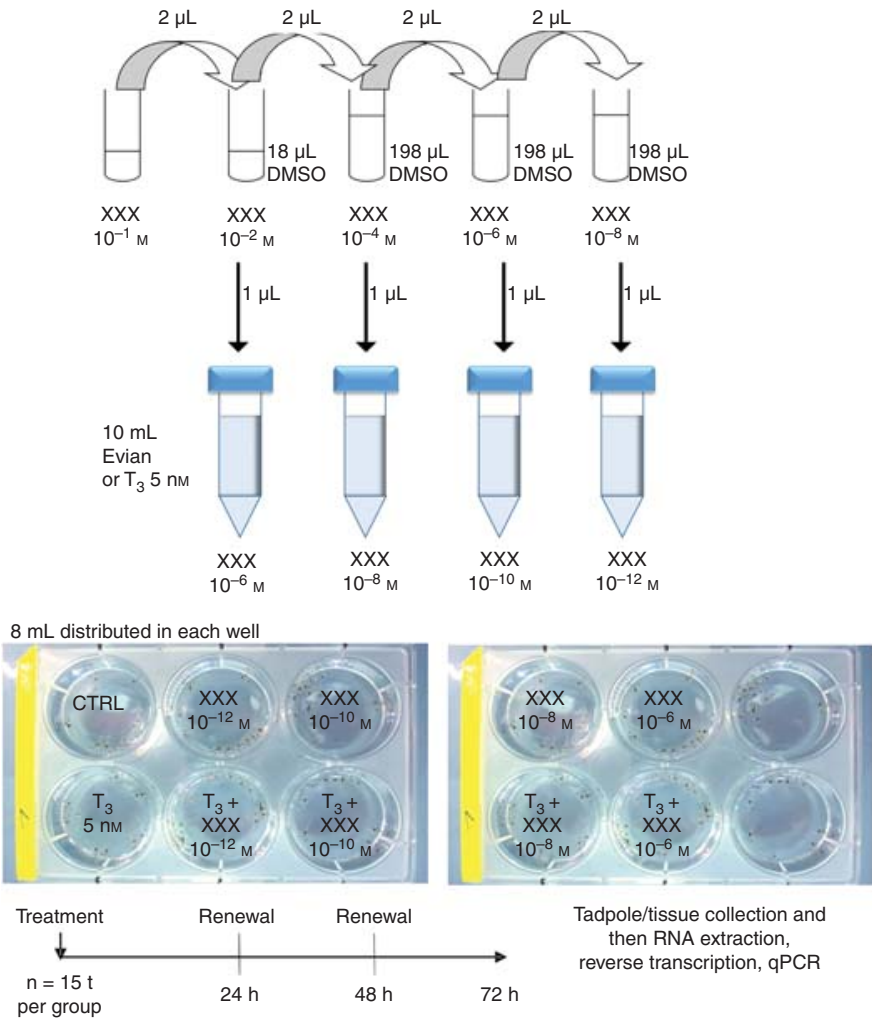

B
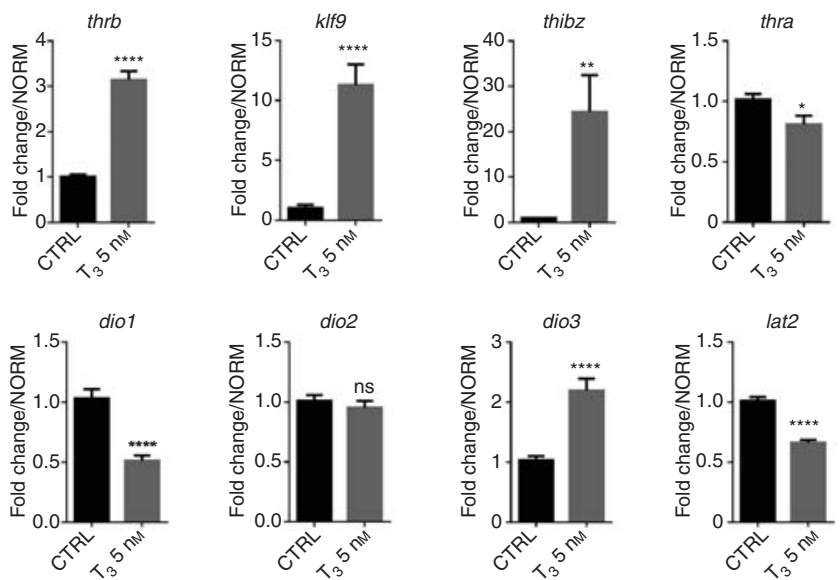

FIGURE 1. (A) Graphical description of treatment. An example is given of a substance to be tested in a starting solution at $10^{-1} \mathrm{M}$ in DMSO. Targeted dilutions are $10^{-12}, 10^{-10}, 10^{-8}$, and $10^{-6} \mathrm{M}$. First, a cascade dilution in DMSO is done to obtain a 10,000 times more concentrated solution than the targeted dilution. Then $1 \mu \mathrm{L}$ of each "mother dilution" is diluted in either $10 \mathrm{~mL}$ of Evian water or $5 \mathrm{~nm} \mathrm{~T}_{3}$ (prepared in Evian water). CTRL or $\mathrm{T}_{3}$ treatments are, respectively, $1 \mu \mathrm{L}$ DMSO in $10 \mathrm{~mL}$ water and $1 \mu \mathrm{L}$ DMSO in $10 \mathrm{~mL} 5 \mathrm{~nm} \mathrm{~T}_{3}$. For each concentration tested, $8 \mathrm{~mL}$ of the prepared solution $(10 \mathrm{~mL})$ are pipetted into the wells and the plates are incubated at $23^{\circ} \mathrm{C}$. Daily renewal is done at a given time. After $72 \mathrm{~h}$, tissues/tadpoles are collected. $(B)$ Quantification of expression of eight typical thyroid hormone-related genes are given as examples obtained in brain tissue after 3-d exposure with $\mathrm{T}_{3} 5 \mathrm{~nm}$. Genes encoding transcription factors up-regulated in brain tissue after a 3-d exposure with $\mathrm{T}_{3}$ are: thyroid hormone receptor beta (thrb) with two- to threefold induction, kruppel like factor 9 (klf9) with a 10-fold induction, and thyroid hormone induced bzip factor (thibz) with a 20- to 30-fold induction. dio3 (encoding the D3 enzyme which inactivates $\mathrm{T}_{3}$ into $\mathrm{T}_{2}$ ) is documented to be up-regulated (two- to threefold induction) by $\mathrm{T}_{3}$ while dio1 (encoding D1) is observed to be down-regulated (twofold reduction) and dio2 (encoding the activating enzyme D2 which converts $\mathrm{T}_{4}$ into $\mathrm{T}_{3}$ ) remains unchanged. Two other genes encoding the nuclear receptor alpha (thra) and the membrane transporter lat2 (lat2) are documented to be down-regulated. These results are the pool of three independent experiments with $n=4$ replicates in each experiment. Total RNA extraction for each replicate was obtained from two brains. $500 \mathrm{ng}$ of total RNA was used for reverse transcription and 1:20 dilution cDNA was used for qPCR. See Table 1 for primers. Fold changes are presented as mean + SEM using histograms. Statistics were done using pairwise nonparametric Mann-Whitney test with $(* * * *) P<$ $0.0001,\left({ }^{* *}\right) P<0.01,(*) P<0.05$. 
RT-qPCR

16. After $72 \mathrm{~h}$ of exposure, rinse the tadpoles by transferring them to a $50 \mathrm{~mL}$ plastic tube containing $40 \mathrm{~mL}$ of room temperature Evian water.

Gene expression can also be assessed after a shorter exposure period e.g., $24 \mathrm{~h}$ exposure.

17. Transfer the tadpoles into a $50 \mathrm{~mL}$ plastic tube containing $100 \mathrm{mg} / \mathrm{L} \mathrm{MS}-222$.

Tadpoles should stop moving after 30 sec.

If interested in gene expression in specific tissues, dissect tissues for RT-qPCR analysis using nuclease-free tools prepared by washing in detergent (RNAseZap or SDS) and $0.1 \mathrm{~N} \mathrm{NaOH}$, followed by at least three washes in MilliQ water and overnight sterilization at $180^{\circ} \mathrm{C}$. Clean tools and the dissection surface frequently with RNAseZap during dissections.

See Troubleshooting.

18. Rinse the tadpoles by transferring them to a $50 \mathrm{~mL}$ plastic tube containing $40 \mathrm{~mL}$ of room temperature Evian water.

19. Place one tadpole per nuclease free microcentrifuge tube containing $100 \mu \mathrm{L}$ of lysis solution from a total RNA extraction kit (e.g., Ambion RNAqueous). From one replicate at least 5 tadpoles (or tubes containing tissues such as two tadpole brains) of each group should be used for the gene expression analysis.

If you intend to perform RT-qPCR on stage 45-47 Xenopus laevis brains, two brains per tube are sufficient to provide enough RNA.

20. Immediately extract RNA using an RNA extraction kit or snap-freeze samples in lysis buffer using liquid nitrogen to process them later. To extract RNA, thaw the samples on ice and continue RNA extraction.

The DNAse I treatment step is important for RT-qPCR, even though it is often listed as optional in the RNA kit manual.

21. Use a Nanodrop spectrophotometer to estimate the obtained RNA concentration of each sample (at this point there should be 20 samples -5 replicates each for chemical of interest in Evian water, chemical of interest in $\mathrm{T}_{3}$, and Evian water and $\mathrm{T}_{3}$ controls). Quality can be checked at this step by looking at the $260 / 280$ and $260 / 230$ ratios.

The 260/280 ratio should be over 1.8 and is expected to be close to 2.0. The 260/230 ratio should be above 2.0. A lower $260 / 230$ ratio may indicate solvent contamination. This contamination can be removed by using specific purification columns (e.g., RNeasy MinElute Cleanup Kit (QIAGEN ref. 74204)).

Note that at this step, transfer RNA, ribosomal RNA, and digested genomic DNA interfere with the quantification of targeted mRNA. A method based on total RNA specific dye (QUBIT) is available for accurate concentration estimation (in samples processed without DNAse treatment, for example, because of usage of TaqMan probes).

22. Determine the integrity and quality of the extracted RNA by estimating the $18 \mathrm{~S} / 28 \mathrm{~S}$ ratios. We recommend the use of an Agilent Bioanalyzer with Agilent RNA 6000 Pico Kit. Only samples with RIN (RNA integrity number) higher than 7.5 should be used for further RT-qPCR. 
P. Spirhanzlova et al.

A standard RNAse free $0.8 \%$ agarose gel could be used if RNA quantity is not limiting. On a gel, in the intact RNA sample the $18 S$ and $28 S$ ribosomal RNA bands should be clearly visible, while degraded RNA should appear as low molecular weight smear. Moreover, the 285 band should be bigger than 185 band.

23. Perform real time-polymerase chain reaction (RT-PCR) using an RT-PCR kit of your choice (e.g., High-Capacity cDNA Reverse Transcription Kit-Applied Biosystems or Reverse Transcription Master Mix-Fluidigm). We usually perform reverse transcription on $125 \mathrm{ng}$ (Fluidigm) to 500 ng (Applied Biosystems) RNA.

Note that the Fluidigm kit precludes doing an RT minus control. While performing RT-qPCR, an RT minus control should be included on the plate. This control is usually prepared during the reverse transcription step by replacing the enzyme reverse transcriptase with water and serves to verify that samples are not contaminated by genomic DNA, which might be amplified during the qPCR reaction. The RT minus control is expected to result in no amplified product. Some kits do not allow omission of reverse transcriptase; in that case RNA at the appropriate concentration should be added directly to the qPCR plate. A water control should be also included on the qPCR plate by replacing the CDNA sample with water. This control serves to verify that primers do not form primer dimers and that the primer mix is not contaminated by DNA.

24. Create your plate schema trying to put all your target and reference genes on the same plate (384well clear hardshell plate). (See Fig. 2 for schema example.) Perform at least duplicates of each sample (triplicates are recommended). Follow the minimum information for publication of quantitative real-time PCR experiments (MiQE) (Bustin et al. 2009).

A list of primers for genes involved in thyroid signaling (e.g., thro, thr $\beta$, dio1, dio2, dio3, thibz, klf9, lat2) is accessible in Table 1. In our example schema, every sample is tested with every primer pair. Do not forget to include at least two reference genes (i.e., those not affected by endocrine disrupters) for normalization. For more information about Xenopus reference genes consult (Mughal et al. 2018).

25. Prepare 1:20 dilutions of each cDNA with nuclease free water (e.g., $5 \mu \mathrm{L}$ of cDNA in $95 \mu \mathrm{L}$ of nuclease free water).

26. Prepare a series of qPCR mixes for each primer pair in Table 1 (genes involved in thyroid signaling in Xenopus). Each mix (target volume $5 \mu \mathrm{L}$ of mix per well) will contain $0.15 \mu \mathrm{L}$ of reverse primer $(10 \mathrm{pM}), 0.15 \mu \mathrm{L}$ of forward primer $(10 \mathrm{pM}), 1.7 \mu \mathrm{L}$ of nuclease free water and $3 \mu \mathrm{L}$ of Power SYBR master mix per reaction. To ensure that sufficient amount of mix is prepared, increase the total volume, corresponding to the number of wells where you use this primer pair (including controls), by $10 \%$. Work on ice.

Volumes have been adapted for minimal reagent consumption with 384-well plates. If a 96-well plate is used, the minimal target volume per well is $13 \mu \mathrm{L}$. In that case the mix contains $0.3 \mu \mathrm{L}$ of forward primer $(10 \mathrm{pm}), 0.3 \mu \mathrm{L}$ of reverse primer (10 pM), $7.5 \mu \mathrm{L}$ of Power SYBR master mix and $4.9 \mu \mathrm{L}$ of nuclease free water per reaction.

27. In each well of the 384-well plate add $1 \mu \mathrm{L}$ of diluted cDNA prepared in Step 25 and $5 \mu \mathrm{L}$ of mix prepared in Step 26. Include a water control $(1 \mu \mathrm{L}$ of nuclease free water and $5 \mu \mathrm{L}$ of qPCR mix per well). Work on ice.

If you use a 96-well plate machine, pipette $2 \mu L$ of diluted cDNA and $13 \mu \mathrm{L}$ of mix prepared in Step 26.

At this step, the use of a multidistribution pipette is recommended.

28. Run $\mathrm{qPCR}$ using a dedicated machine and program to provide comparative $\mathrm{C}_{\mathrm{t}}$ measurements including melting curve. An example is the QuantStudio 6 flex QPCR machine (Life technologies) with Quant Studio program.

qPCR Analysis

A brief description of qPCR analysis is provided below. For a more detailed explanation and other options of analysis refer to Bustin et al. 2009; Livak and Schmittgen 2001; Nolan et al. 2006; or Pfaffl 2001.

29. Export $C_{t}$ values of your samples. If you worked with sample duplicates or triplicates as recommended, calculate the mean $\mathrm{C}_{\mathrm{t}}$ values for each sample.

30. In MS Excel calculate the geometric mean of the $C_{t}$ values of reference genes for each sample (e.g., geometric mean of the $\mathrm{C}_{\mathrm{t}}$ values of $e f 1 \alpha$ and $o d c$ for each individual sample). 


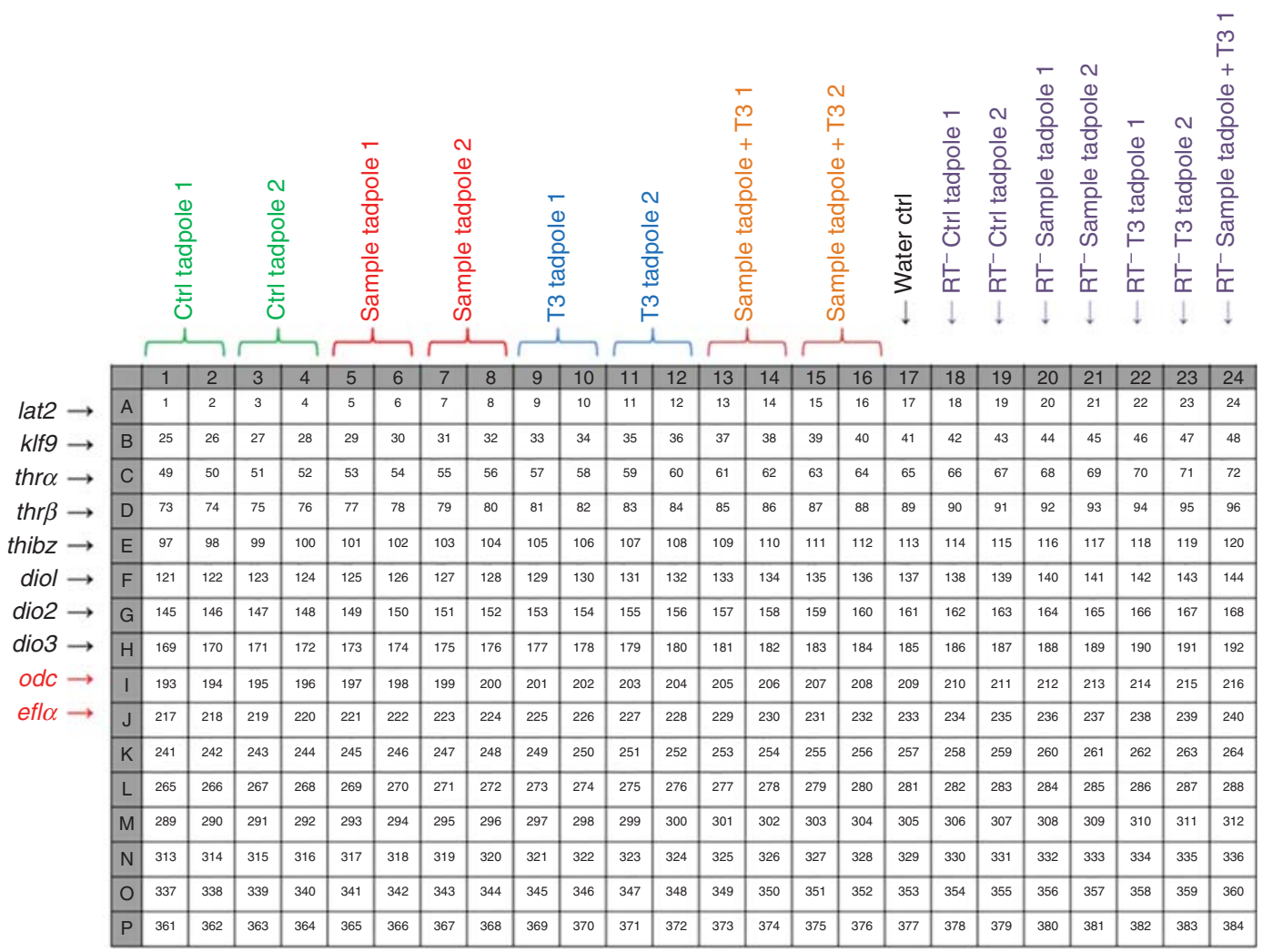

FIGURE 2. Schema of 384-well plate for qPCR. First, each column is filled with $1 \mu \mathrm{L}$ of diluted cDNA (1:20). For example, column 1 is filled with $1 \mu \mathrm{L}$ of 1:20 cDNA synthetized from RNA extracted from control tadpole \#1. Column 2 is filled with diluted cDNA corresponding to control tadpole \#2, etc. Note, that only 2 samples per group are depicted on this schema. Preferably, create a plate schema which includes all groups present in the experiment (in this case Evian control, sample in Evian, $T_{3}$ control, and sample in $T_{3}$ ). We aim to analyze gene expression of at least five samples from the same group per experimental replicate. The gene expression study described in this protocol would require three qPCR plates in total. In addition to this example plate, a second plate would include groups ctrl tadpoles 3 and 4 (columns 1-4), sample tadpoles 3 and 4 (columns 5-8), $T_{3}$ tadpoles 3 and 4 (columns 9-12), and sample $+\mathrm{T}_{3}$ tadpoles 3 and 4 (columns 15-16). The last plate would contain the remaining samples (number 5) of each group. Water control wells (column 17) contain $1 \mu \mathrm{L}$ of nuclease free water. RT- wells (columns 17-24) contain $1 \mu \mathrm{L}$ of RT reaction run without the presence of reverse transcriptase if the RT kit allows that. If the reverse transcriptase is not provided separately in the kit, RNA of the corresponding sample can be used instead (1.25 ng per well). In the second step, $5 \mu \mathrm{L}$ of qPCR mixes with primers specific for each gene is added to corresponding rows including water and $\mathrm{RT}^{-}$ rows. For example, mix containing reverse and forward primers for the gene lat2 is distributed to the entire row $\mathrm{A}$. It is always better to avoid placing your reference genes (in red) at the border rows of your plate (row A and P) to avoid possible drying of the wells.

31. Subtract the geometric mean of the $C_{t}$ values of reference genes from the $C_{t}$ values of your sample in order to calculate the $\Delta \mathrm{C}_{\mathrm{t}}$ values $\left(=\mathrm{C}_{\mathrm{t}}\right.$ of the gene of interest - geometric mean of reference genes of the same sample).

32. Calculate a median value of the $\Delta \mathrm{C}_{\mathrm{t}}$ values of all genes in the control group. This is a normalization step, if you wish to normalize to another group (e.g., $\mathrm{T}_{3}$ ), calculate a median of this group.

33. Subtract the median value of the control group from the $\Delta \mathrm{C}_{\mathrm{t}}$ value of your sample to create a $\Delta \Delta \mathrm{C}_{\mathrm{t}}$.

34. Calculate a fold change using the formula $=2^{-\Delta \Delta \mathrm{Ct}}$.

35. Use a program to perform a statistical analysis of the data (e.g., GraphPad Prism).

Several examples of typical gene expression patterns of $72 \mathrm{~h}$ exposure to $5 \mathrm{~nm} T_{3}$ solution are shown in Fig. $1 B$.

See Troubleshooting. 
P. Spirhanzlova et al.

Imaging (Optional)

Today many laboratories use in vivo bioassays based on transgenic organisms featuring genetic constructs driving expression of fluorescent proteins to link gene expression with physiological effects. If using a transgenic Xenopus laevis line expressing GFP (e.g., Tg(thibz:GFP) (Fini et al. 2007)), fluorescence can be quantified as described below. Changes in fluorescence are a result of potential disruption at multiple levels; synthesis, transport and/or metabolism of thyroid hormones in response to endocrine disruption.

36. After $72 \mathrm{~h}$ of exposure, rinse the tadpoles with Evian water in a $50 \mathrm{~mL}$ plastic tube as in Step 16.

37. Transfer the tadpoles into a $50 \mathrm{~mL}$ plastic tube containing $\sim 40 \mathrm{~mL}$ of $100 \mathrm{mg} / \mathrm{L} \mathrm{MS}-222$.

38. Use a $2 \mathrm{~mL}$ transfer pipette with cut tip to place the tadpoles (one tadpole per well) in a black conical well 96-well plate. Leave an empty well between each group (for example, we test four groups: a control Evian group, a control $\mathrm{T}_{3}$ group, a sample diluted in Evian group, and a sample diluted in $\mathrm{T}_{3}$ group. There are 15 tadpoles in each group. These tadpoles should be plated consecutively with one empty well between groups).

39. Using a fine transfer pipette, position each tadpole in its well. The appropriate position of the tadpole will depend on which organ expresses GFP in the transgenic line you are using. For instance, if you wish to photograph the brain, place the tadpole dorsally so the ventral surface is uppermost. Make sure that the head of the tadpole is positioned in the middle of the well and the tail is curled around the body. Remove the majority of liquid.

40. Take color images with a $25 \times$ objective and 3 sec exposure time using a fluorescence microscope equipped with GFP long pass filters. QC Capture pro (QImaging) software can be used for image acquisitions.

See Troubleshooting.

41. At the end of the experiment, fill each well with $1 \mathrm{~g} / \mathrm{L}$ MS-222 to euthanize the tadpoles and dispose of the carcasses appropriately.

Image Analysis and Statistics

42. Open all images of one exposure group in ImageJ.

43. Exclude nonspecific signals by splitting the image into three layers (red, blue, and green channels) followed by subtraction of the red and blue channel from the green one.

44. Calculate the integrated density of the green channel. The data are expressed in relative units of fluorescence (RFU).

45. Use an appropriate program for statistical analysis of the data (e.g., GraphPad Prism).

See Troubleshooting.

Problem (Step 6): No amplexus occurred; female doesn't produce any eggs; eggs are not fertilized.

Solution: Respect the recommended intervals between breedings ( $2 \mathrm{wk}$ and $4-6$ mo for males and females, respectively). Select females with prominent cloaca and pear-shaped bodies and males with dark nuptial pads at the inner side of forelimbs. Increase the amount of hCG injected in the females—never exceed 700 units—and preprime them in the morning with 50-100 units.

Problem (Step 8): High mortality of the tadpoles before NF stage 45.

Solution: Verify that the water temperature doesn't drop below $21^{\circ} \mathrm{C}$. Change the water every time it becomes turbid. 
Problem (Step 8): Tadpoles develop slowly or are small.

Solution: Verify that the water temperature doesn't drop below $21^{\circ} \mathrm{C}$. An optimal solution is to place the tank into $23^{\circ} \mathrm{C}$ incubator.

Problem (Step 14): High mortality of the tadpoles during exposure not related to the toxicity of test compound.

Solution: Put the tadpoles into six-well plates $24 \mathrm{~h}$ before start of exposure and keep them overnight in a $23^{\circ} \mathrm{C}$ incubator. If the mortality exceeds $10 \%$ the experiment should not be considered valid and should be stopped.

Problem (Step 17): Tadpoles keep moving after the anaesthesia with MS222.

Solution: Verify that the MS222 solution is not older than 3 wk and that it was stored in the dark (old MS222 or MS222 exposed to light turns yellow).

Problem (Steps 35 and 45): $\mathrm{T}_{3}$ induction is not detected.

Solution: Make sure that the correct dilution was used. Do not use stock stored at $-20^{\circ} \mathrm{C}$ after $1 \mathrm{yr}$ of storage. Prevent usage of plastic during the process (we have validated that the use of low binding tips, $5000 \mu \mathrm{L}$ tips, and six-well plate (TPP) is okay); for example, do not use a manual dispenser (e.g., Eppendorf Varispenser).

Problem (Step 40): Tadpoles have strong yellow color under the fluorescence microscope.

Solution: Yellow color of tadpoles may interfere with image analysis and create false positive results. If the yellow signal seen under the fluorescent microscope is in the head region of the tadpoles, they are probably dead and possibly dry, potentially due to slow manipulation. Plate only as many tadpoles at the same time as you can position and photograph within $30-45 \mathrm{~min}$. A yellow signal at the level of the intestines/yolk is frequent in tadpoles younger stage than stage 46 . The gut area can be cropped away using the program Image J before further image analysis.

Amphibian metamorphosis is a thyroid hormone-dependent process, hence its use in the AMA (amphibian metamorphosis assay) OECD test guideline (OECD TG 231; Opitz et al. 2005). However, given the unknown endocrine-disrupting potential of the large numbers of chemicals currently on the market or to be tested before marketing, it is crucial to develop more rapid in vivo bioassays. Our group developed a 3-d test using a transgenic Xenopus line $\operatorname{Tg}$ (thibz:GFP) (Fini et al. 2007). This line harbors a genetic construct composed of the thyroid response elements upstream of the coding sequence for the transcription factor TH/bZIP that drives GFP expression with a thyroid hormone stimulus. This test is currently undergoing final validation at the level of the OECD as the Xenopus Embryonic Thyroid Assay (XETA). Using this principle of a fluorescent reporter upstream of a promoter specific for an endocrine response, a number of transgenic teleost lines have been developed to detect steroidal disruption (Brion et al. 2012; Sébillot et al. 2014; Spirhanzlova et al. 2015). Here, we describe a more general exposure protocol using wild type Xenopus laevis larvae to address effects of endocrine disruptors on gene expression. Besides the evolutionary conservation of TH signaling and brain development, the amphibian model provides experimental access to early critical windows of development that are essential for optimal later development, including that of the nervous system. This protocol has been used mainly for detecting chemicals with thyroid hormone disrupting capacities but could also be used with adjustments for critical windows appropriate for other endocrine axes. Aquatic embryo models have the additional advantages of having external 
P. Spirhanzlova et al.

development and large numbers of larvae produced by the female at each mating. In addition, early developmental stages of fish and tadpoles, which still feed from their reserves of yolk, are not classed as laboratory animals under European Union regulations (Directive 2010/63/EU).

\section{RECIPES}

\section{3,3',5-Triiodo-L-Thyronine Sodium Salt Solution $\left(T_{3} ; 5 n м\right)$}

1. Make a $0.01 \mathrm{M}$ stock solution of $\mathrm{T}_{3}$ by adding $100 \mathrm{mg}$ of $\mathrm{T}_{3}$ powder (Sigma-Aldrich; CAS 55-06-1) to $14.86 \mathrm{~mL}$ of $30 \% \mathrm{NaOH}$ (prepared in Milli-Q [ultrapure] water). Vortex the $0.01 \mathrm{~m}$ stock solution well, aliquot, and store at $-20^{\circ} \mathrm{C}$.

2. Make a $0.0001 \mathrm{M}$ intermediate solution of $\mathrm{T}_{3}$ fresh every day by adding $5 \mu \mathrm{L}$ of $0.01 \mathrm{M}$ stock solution of $\mathrm{T}_{3}$ to $495 \mu \mathrm{L}$ of Evian water (use Evian water in a $75 \mathrm{cL}$ glass bottle or another mineral water with reproducible quality).

Be careful that neither precipitate nor crystals are present in the $T_{3}$ stock solution.

3. Add $5 \mu \mathrm{L}$ of $0.0001 \mathrm{~m} \mathrm{~T}_{3}$ to $100 \mathrm{~mL}$ of Evian water to create a final $5 \mathrm{~nm} \mathrm{~T}_{3}$ solution.

MS222 Solution (0.1\%)

MS222 (Sigma-Aldrich, A5040)

$1 \mathrm{~g}$

Sodium bicarbonate (Sigma-Aldrich, S5761) $1 \mathrm{~g}$

Water, dechlorinated

$1 \mathrm{~L}$

Protect from light. Store for up to $2 \mathrm{wk}$ at room temperature.

\section{ACKNOWLEDGMENTS}

We thank Sébastien Le Mével for his input on the methods that are routinely used. We thank Gérard Benisti, Philippe Durand, and Jean-Paul Chaumeil for animal care. This protocol has been refined thanks to work supported by grants from Centre National de la Recherche Scientifique (CNRS), Muséum National d'Histoire Naturelle (MNHN), and from French Ministry of Environment MEDD, PNRPE_THYDIS 2013-N ${ }^{\circ}$ CHORUS-2101207963, PNREST THYPEST EST-2014-122, and European Union EDC MIX RISK_GA N634880.

\section{REFERENCES}

Brion F, Le Page Y, Piccini B, Cardoso O, Tong SK, Chung B, Kah O. 2012. Screening estrogenic activities of chemicals or mixtures in vivo using transgenic (cyp19alb-GFP) zebrafish embryos. PLoS One 7: e36069.

Bustin SA, Benes V, Garson JA, Hellemans J, Huggett J, Kubista M, Mueller R, Nolan T, Pfaffl MW, Shipley GL, et al. 2009. The MIQE guidelines: Minimum information for publication of quantitative real-time PCR experiments. Clin Chem 55: 611-622.

Fini JB, Le Mevel S, Turque N, Palmier K, Zalko D, Cravedi JP, Demeneix BA. 2007. An in vivo multiwell-based fluorescent screen for monitoring vertebrate thyroid hormone disruption. Environ Sci Technol 41: 5908-5914.

Fini JB, Le Mével S, Palmier K, Darras VM, Punzon I, Richardson SJ, Clerget-Froidevaux MS, Demeneix BA. 2012. Thyroid hormone signaling in the Xenopus laevis embryo is functional and susceptible to endocrine disruption. Endocrinology 153: 5068-5081.

Fini JB, Mughal BB, Mével SL, Leemans M, Lettmann M, Spirhanzlova P, Affaticati P, Jenett A, Demeneix BA. 2017. Human amniotic fluid contaminants alter thyroid hormone signalling and early brain development in Xenopus embryos. Sci Rep 7: 43786.
Lim W, Nguyen NH, Yang HY, Scanlan TS, Furlow JD. 2002. A thyroid hormone antagonist that inhibits thyroid hormone action in vivo. J Biol Chem 277: 35664-35670.

Livak KJ, Schmittgen TD. 2001. Analysis of relative gene expression data using real-time quantitative PCR and the $2^{-\Delta \Delta \mathrm{C}_{\mathrm{T}}}$ Method. Methods San Diego Calif 25: 402-408.

Mughal BB, Leemans M, Spirhanzlova P, Demeneix B, Fini JB. 2018. Reference gene identification and validation for quantitative real-time PCR studies in developing Xenopus laevis. Sci Rep 8: 496.

Nieuwkoop PD, Faber J. 1994. Normal table of Xenopus laevis (Daudin): A systematical and chronological survey of the development from the fertilized egg till the end of metamorphosis. Garland Publishing, New York.

Nolan T, Hands RE, Bustin SA. 2006. Quantification of mRNA using realtime RT-PCR. Nat Protoc 1: 1559-1582.

OECD. 2009. Test No. 231: Amphibian metamorphosis assay, OECD Publishing, Paris.

Opitz R, Braunbeck T, Bögi C, Pickford DB, Nentwig G, Oehlmann J, Tooi O, Lutz I, Kloas W. 2005. Description and initial evaluation of a Xenopus metamorphosis assay for detection of thyroid system-disrupt- 
ing activities of environmental compounds. Environ Toxicol Chem 24: 653-664.

Pfaffl MW. 2001. A new mathematical model for relative quantification in real-time RT-PCR. Nucleic Acids Res 29: e45.

Sébillot A, Damdimopoulou P, Ogino Y, Spirhanzlova P, Miyagawa S, Du Pasquier D, Mouatassim N, Iguchi T, Lemkine GF, Demeneix BA, et al. 2014. Rapid fluorescent detection of (anti)androgens with spiggin-gfp medaka. Environ Sci Technol 48: 10919-10928.
Spirhanzlova P, Leleu M, Sébillot A, Lemkine GF, Iguchi T, Demeneix BA, Tindall AJ. 2015. Oestrogen reporter transgenic medaka for non-invasive evaluation of aromatase activity. Comp Biochem Physiol C Toxicol Pharmacol 179: 64-71.

Turque N, Palmier K, Le Mével S, Alliot C, Demeneix BA. 2005. A rapid, physiologic protocol for testing transcriptional effects of thyroid-disrupting agents in premetamorphic Xenopus tadpoles. Environ Health Perspect 113: 1588-1593. 


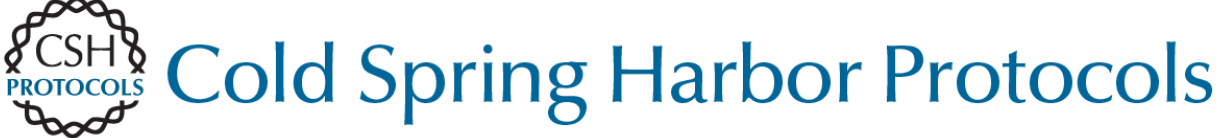

\section{Following Endocrine-Disrupting Effects on Gene Expression in Xenopus laevis}

Petra Spirhanzlova, Michelle Leemans, Barbara A. Demeneix and Jean-Baptiste Fini

Cold Spring Harb Protoc; doi: 10.1101/pdb.prot098301 originally published online July 24, 2018

\begin{tabular}{|c|c|}
\hline $\begin{array}{l}\text { Email Alerting } \\
\text { Service }\end{array}$ & Receive free email alerts when new articles cite this article - click here. \\
\hline $\begin{array}{l}\text { Subject } \\
\text { Categories }\end{array}$ & $\begin{array}{l}\text { Browse articles on similar topics from Cold Spring Harbor Protocols. } \\
\text { Analysis of Gene Expression (197 articles) } \\
\text { Analysis of Gene Expression, general (129 articles) } \\
\text { Fluorescence ( } 517 \text { articles) } \\
\text { Fluorescence, general (341 articles) } \\
\text { Polymerase Chain Reaction (PCR) (139 articles) } \\
\text { Polymerase Chain Reaction (PCR), general (184 articles) } \\
\text { Visualization of Gene Expression (127 articles) } \\
\text { Xenopus (210 articles) }\end{array}$ \\
\hline
\end{tabular}

